\title{
Study on Effect of China "One belt, one road's" Construction on the World Economy
}

\author{
Zhennan Wu \\ China Tianjin 300000 \\ Tianjin Communication Network Engineering Chamber of Commerce, the Vice president
}

Keywords: "One belt, One road"; World economy; Global cooperation

\begin{abstract}
One belt, One road"'s construction is different to the regional economic cooperation and the global construction of regional cooperation construction. It is based on the slow growth of global economic growth in recent years, the rapid development of the US's two strategies and the important period of China's economic restructuring. It will bring strong impetus to the Asia Pacific Regional Cooperation and the development of the global economy.

The so-called "One belt, One road", is the Silk Road Economic Zone and Maritime Silk Road. This "One belt, One road"'s construction thought is the extension and inheritance of the ancient Silk Road historical elements with the economic development strategy of the proposed tolerance and openness, cooperation and win-win idea.
\end{abstract}

\section{Part One Essential Essence and Strategic Significance of "One belt, One road"}

\section{Connotation and Historical Significance of "One belt, One road"}

In the spring and Autumn period, China had a lot of trade contacts with the current Asian and European continent. In the Han Dynasty, trade contacts were gradually monopolized by the government and increased the scope of trade. In the Western Han Dynasty, Qian Zhang made the western region, and the silk route was opened up. The concrete route of the silk road is from Changan to Luoyang to Xinjiang, Gansu, connecting the western and Western Asia, and through the continental fortress of the Mediterranean. The trade between the silk road not only involves silk, but also in Song Dynasty, which is mainly based on spices and porcelain, but it is still named after silk, which shows the national tradition and historical significance of China.

\section{Strategic Significance of "One belt, One road"}

"One belt, One road"'s construction idea was first proposed by general secretary Jinping Xi, led to the close attention of all countries worldwide. "One belt, One road"s construction thought foreign tenet is to establish East Asia and West Asia and Eastern Europe international trade channels, the trade channels including more than 60 countries throughout the Pacific and India ocean. The inner purpose of the whole area is to connect to eighteen provincial administrative units such as Xinjiang and Chongqing to promote the harmonious development of all regions in China.

Although China's economic development over the years is getting faster and faster, its quality is not commensurate with the speed. It is generally shown in:

The Industrial Layout Needs to be Improved. China's industry and public infrastructure are mostly in the eastern and coastal areas. If other countries take military aggression or economic sanctions against China, they will easily lead to the destruction of industrial construction and even the rapid decline of the economy.

China's Oil Resources are Relatively Scarce. The energy development of coal mines is too fast, and the resources available are relatively few. Therefore, the dependence of oil resources on foreign countries is gradually improving. It is easy to lead to the implementation of price control by foreign economic institutions.

China's Overcapacity is Overcapacity. The reality is that the surplus capacity of our country is exactly the need for some backward countries. For example, steel and cement, the price of cement in African countries is about $\$ 30$ per ton, and at home, it can sell to $\$ 50$ per ton. "One belt, One road" construction idea is used to solve the overcapacity, and the production capacity of China's 
remaining energy transfer to the relatively backward countries, in this way, not only to achieve the optimization of our industrial structure reform, and promote the development of other countries, achieve multi-party win-win cooperation.

\section{Part Two Impact of "One belt, One road" on the World Economy}

With the rapid development of information globalization, each country gradually trade their economic relations more closely. In such a world economic environment, China's trade still has a considerable space for progress. The idea of "One belt, One road" turned out to give a new opportunity for the construction of our country, it also provides a great help for the economic development along the country and the world.

"One belt, One road" Contributes to the Optimization of China's Economic Structure, Reduces the Gap between What the Ministry of Construction

Since 1980s, our country's economy has developed rapidly in geometric form, and people's living standard has been greatly improved, and the happiness index is also rising. Secretary Xiaoping Deng's idea of reform and opening up has made the coastal special economic zones such as Guangzhou and Shenzhen flourish and promoted the development of the eastern regional economy. However, the only drawback is that the economic construction in the Midwest is relatively short of notable achievements. The construction and development of the eastern part of China is much faster than that in the west, but the energy in the west is very rich, but it is a pity that it can not be effectively exploited and utilized. Therefore, the proposed "One belt, One road"construction idea, and increasing along the country's trade, the western region to produce all-round, three-dimensional and cooperation between countries along. For example, to optimize the business environment, to create a fair trading platform, eliminate trade restrictions; broaden the world of enterprises and the construction of the West investment and financing channels; to promote new energy and new technology, learning and communication, promote business cooperation system implementation; supervise the strength of the western enterprises in overseas and in the future, to actively join the country along in economic construction, in the coastal areas of the transport hub to create trade zone and industrial zone, China construction has the features of national industry, the coordinated development of our development, complementary advantages for different industries. Under this background, it not only increased the openness of the western regions, but also realized the common construction of the East and the west, and coordinated the overall development of China's economy.

"One belt, One road" Helps Countries Along the Regional Resource Sharing, Win-win Development

The speed of economic construction along the countries along the line is uneven, but it can be complementary to each other according to the differences of their respective advantages. In order to optimize the industrial structure, China can adjust the overcapacity industry to relatively backward countries, to achieve the sharing of resources, so as to achieve multi - win. Concept of "One belt, One road"under the guidance can give full play to the industrial advantages, make full use of the market mechanism, so that all countries along the income, which greatly shortens the gap between the rich and the poor, improve the regional development that is not balanced, which is conducive to the creation of numerous world economy's win-win.

\section{"One belt, One road"'s Strategic Concept Adapts to the Reform of the World Economic System Social Trend}

With the outbreak of the economic crisis in 2008, the pace of the world's economic development has slowed down obviously showing the trend of fatigue. The economic structure is very uneven, and needs to be improved urgently. However, some developed western countries, on the surface, want to speed up the improvement of the global economy, but in fact, they do not want to lose their control of the world economy. Our country puts forward "One belt, One road" construction idea, in developing Asia as the core, with trade, it pays more for each country along the public facilities and products in the market in order to jointly create new economy growth, and therefore more fully show the Chinese world economic system reform thought and confidence. 


\section{"One belt, one road" Contributes to the Construction of the Asia Pacific and Europe}

The strategic thought of One belt, One road" leads and under the influence of the development of various countries along to better, it is necessary to change the traditional independent self development ideas, along with other countries, if should be coordinated development, taking the initiative to change the development mode of thinking and initiative, and promoting the cooperation of Asia Pacific and European regions. "One belt, One road" will help strengthen the national trade and exchange with a solid foundation for each country's diplomatic exchanges creatinga win-win trading platform and the construction environment and win-win help to build the Asia Pacific and Europe.

\section{"One belt, One road" Gives a New Way of Economic Cooperation in the World.}

In the present time, the governments of all countries have paid more and more attention to economic diplomacy. Compared with the previous focus on diplomacy for economic services, it is clear that this is a substantial change. This is also the necessary need for China to join the global management. In the process of China's gradual development, it is necessary to integrate the future economic development and diplomacy, otherwise it will be difficult to join in the global management in essence, or to participate in the construction of the global rules in essence. The core idea of "One belt, One road" is global and win-win, the purpose is to let the interests of the countries along the formation of a solid body. It aims to make the economic development strategy of the related countries effective connection and integration and common development. During the state visit of general secretary Jinping Xi to Russia, after the talks between Jinping Xi and Putin, the two sides signed and issued a joint statement on the docking and cooperation of the construction of the Silk Road Economic Belt and the Eurasian Economic Alliance. According to the joint statement, the two countries will promote comprehensive docking and cooperation and development of the Silk Road economy development and the Eurasian Economic Union body to ensure sustained and rapid development of regional economy, speeding up the process of regional economic integration, stable development and urge all regions. In addition, China and South Korea's "Eurasian initiative" also realized docking. This is a concept proposed by Korea in 2013 to increase the economic joint development of the countries of South Korea and the Eurasian region and to strengthen their foreign trade. The main joint object of this concept is China, Russia and various countries in Central Asia. This idea is proposed with the South Korean Chinese "One belt, One road" construction goal which is to strive to unite, and Eurasia countries maximizes the mutual cooperation and collaborative development. Over the years, China and South Korea have increased cooperation in other fields, such as economy, trade, energy and services.

\section{"One belt, One road" Contributes to the Construction Strategy of Constructing a New Mode of Regional Economic Cooperation.}

These years, with the increasing development trend of information globalization and regional economic integration environment, emerge in an endless stream, all kinds of new ideas for economic cooperation in the Asia Pacific region and the "One belt, One road" and other cooperation strategy is: one is to set the irregular obstacles to cooperation, which does not limit the geographical scope, and try to avoid the requirements of closed thinking, high participation, as long as it is hoped that cooperation countries will join in, and advocates of different ethnic groups and different history with different economic level of the country to cooperate, especially to develop a joint trade with Asian and European markets, this is a Chinese proposed, a new global strategic cooperation and win-win world. The second is to pay attention to inclusive and win-win ideas. "One belt, One road" is stable and harmonious, open and flourish, complementary and win-win idea, and strives to promote the maximum practical cooperation and win-win economic union to create mutual trust, economic integration and cultural compatibility. It can be said that The Belt and Road construction strategy is China worldwide cooperation in the field of classic.

\section{Conclusion}

"One belt, One road"is on the basis of the trend of world economic development and create economic development concepts and ideas having a significant effect on the economic development 
of Chinese it not only, also affects the development of the world economy. "One belt, One road"'s Initiative countries along the abundant energy and complementary advantages, so countries with good conditions and the premise of cooperation. The "One belt, One road" puts forward which will be along the various countries economic development has great role in promoting, at the same time, but also promote the development of the central and western regions of our country to a great extent. Therefore, we believe that the "One belt, One road"will lead the great rejuvenation of the Chinese nation to promote the rapid and stable development of national economic construction.

\section{Reference}

[1] Yaqin He.Global perspective of "One belt, One road"[J].Journal of Shanxi Datong University (Social Science). 2015(06)

[2] Anyin Jiang. "One belt, One road"'s development experience in the construction of mutual learning -- Taking the infrastructure construction as an example[J].China's Circulation Economy. 2015(12)

[3] Xiaodong Fu.Study "One belt, One road"on the establishment and perfection of the platform from the perspective of regional economics[J].China's Circulation Econom. 2015(12) 